\title{
Carbon Monoxide Diffusing Capability Test
}

National Cancer Institute

\section{Source}

National Cancer Institute. Carbon Monoxide Diffusing Capability Test. NCI Thesaurus.

Code C38083.

A measurement of carbon monoxide (CO) transfer from inspired gas to pulmonary capillary blood. During the test, the subject inspires a gas containing CO and one or more tracer gases to allow determination of the gas exchanging capability of the lungs. 